\title{
LA FAMILIA COMO DERECHO HUMANO DE LA COMUNIDAD LGBTI EN COLOMBIA*
}

\author{
Ángela Patricia Bernal Guzmán**
}

Fecha de recepción: 20 de mayo de 2014

Fecha de evaluación: 24 de junio de 2014

Fecha de aprobación: 15 de diciembre de 2014

Artículo de reflexión

DOI:http://dx.doi.org/10.18359/dere.932

Forma de citación: Bernal, A. (2015). La familia como derecho humano de la comunidad LGBTI en Colombia. Revista Prolegómenos Derechos y Valores, 18, 36, 29-46. DOI:http://dx.doi.org/10.18359/dere.932

\section{Resumen}

La protección de la familia y la igualdad son derechos humanos consagrados en un sinnúmero de instrumentos internacionales y en la Constitución Política de Colombia, que en nuestro país no tienen cabida para aquellas personas del mismo sexo que deciden conformar una familia, pues en la actualidad, con conceptos de orden moral y religioso se ha impedido esta forma de familia. El presente artículo pretende analizar y sustentar la necesidad de un cambio conceptual y constitucional respecto a la protección de los derechos humanos de las parejas del mismo sexo que decidan configurar una familia, teniendo en cuenta las posiciones contrarias con el fin de defender la tesis de que la institución del matrimonio para parejas del mismo sexo, debe soportarse en una nueva noción constitucional del artículo 42 de la Carta Política para poder, en adelante, modificar las normas que desarrollan dicho artículo.

\section{Palabras clave:}

Familia, matrimonio, parejas del mismo sexo, derechos humanos.

\section{FAMILY AS A HUMAN RIGHT OF THE LGBTI COMMUNITY IN COLOMBIA}

\section{Summary}

The protection of family and equality are human rights established in a number of international instruments as well as the Political Constitution of Colombia, these however no place for people of the same sex who decided to have a family, since at present, moral and religious concepts have prevented this kind of family to exist. This article seeks to analyze and support the need for a conceptual and constitutional change regarding the protection of human rights of same-sex couples who decide to have a family, given the opposing positions, in order to

Este artículo corresponde a la investigación desarrollada para optar al título de magíster en Derecho Público para la Gestión Administrativa de la Universidad de los Andes.

* Abogada, candidata a magíster en Derecho Público para la Gestión Administrativa de la Universidad de los Andes. Correo electrónico: bernalguzmanangelapatricia@gmail.com 
defend the thesis that the institution of marriage for same-sex couples should be supported on a new constitutional notion of article 42 of the Constitution, to henceforth change the rules implementing that article.

\section{Keywords:}

Family, marriage, same-sex couples, human rights.

\section{A FAMÍLIA COMO UM DIREITO HUMANO DA COMUNIDADE LGBTI NA COLÔMBIA}

\section{Resumo}

A protecção da família e a igualdade são direitos humanos consagrados em uma série de instrumentos internacionais e na Constituição Política da Colômbia, que no nosso país não tem lugar para pessoas do mesmo sexo que decidam formar uma família, uma vez que, actualmente, por causa de conceitos de ordem moral e religiosa este tipo de família tem algumas restrições para poder formar-se. Este artigo tem por objetivo analisar e apoiar a necessidade de uma mudança conceitual e constitucional relativa à protecção dos direitos humanos dos casais do mesmo sexo, que decidam criar uma família, tendo em conta as posições opostas a fim de defender a tese de que a instituição do casamento para casais do mesmo sexo deve ser apoiada numa nova noção constitucional do artigo 42 da Constituição para mudar de agora em diante as regras de execução do referido artigo.

\section{Palavras-chave:}

Família, casamento, casais do mesmo sexo, direitos humanos.

\section{A. Introducción}

A partir del informe de la organización Colombia Diversa ${ }^{1}$, titulado Situación de derechos humanos de la población LGBT (2010), en el que se afirma que en Colombia la población homosexual es del 10\%y que en la actualidad más de 300.000 colombianos viven en unión libre con parejas del mismo sexo, surge la necesidad de promover un cambio desde nuestra Carta Magna que le permita a la comunidad LGBTI $^{2}$ gozar del respeto y la

1 Organización no gubernamental que trabaja en favor de los derechos de lesbianas, gais, bisexuales, transgeneristas e intersexuales (personas LGBTI) en Colombia, cuya misión es promover la plena inclusión, el respeto de la integralidad de los derechos, el reconocimiento y la movilización de las personas LGBTI en los ámbitos económico, social, político y cultural, con la finalidad de coadyuvar en la construcción de una sociedad democrática, moderna y con justicia social.

2 El propósito central del presente artículo es la consagración constitucional de las nuevas formas de familia, razón por garantía de sus derechos fundamentales no solo como individuos sino también como familia, ello con ocasión de las recientes decisiones judiciales que se imparten respecto al tema:

\footnotetext{
la cual es lógico pensar en la inclusión total de la comunidad LGBTI, pues se parte del criterio general y objetivo de orientación sexual, entendiéndose como la atracción emocional, romántica, sexual o afectiva duradera hacia otros que se distingue fácilmente de otros componentes de la sexualidad que incluyen sexo biológico, identidad sexual y el rol social del sexo, incluyéndose así en este concepto desde la heterosexualidad exclusiva hasta la homosexualidad exclusiva, incorporando diversas formas de bisexualidad, en las que individuos bisexuales pueden experimentar una atracción sexual, emocional y afectiva hacia personas de su mismo sexo y del sexo opuesto (American Psychological Association, 2014), no siendo oportuno ni pertinente hacer abstracciones que generan discusiones de tipo psicológico, médico o científico que no aportan mayores argumentos para
} alcanzar la finalidad que se trazó. 
Tras admitir tutela instaurada por la Fundación Marido y Mujer en coadyuvancia al mismo recurso interpuesto por la Procuraduría General de la Nación, el juez 44 Civil Municipal del Circuito anuló el matrimonio celebrado entre dos mujeres por el Juzgado 44 Civil Municipal de Bogotá el pasado 4 de octubre (El Espectador, 18 de octubre de 2013, párr. 1).

Cambio que se hace necesario a pesar de los pasos en pro de la defensa de los derechos de la población LGBTI dados por el poder legislativo y la Corte Constitucional, ya que no se ha logrado un consenso al respecto, es decir, se sigue desconociendo en la práctica tanto los instrumentos internacionales en la materia como también las necesidades y derechos de esta población.

Tal vez son estos los fundamentos del senador Armando Benedetti, para impulsar un proyecto de ley que tiene como propósito modificar las disposiciones del Código Civil colombiano que consagran al matrimonio como figura única y exclusiva para parejas conformadas por un hombre y una mujer, iniciativa que se materializó en los proyectos de ley 47 y 67 de 2012 del Senado y Cámara respectivamente (Benedetti, 2012), y que busca cumplir con la orden impuesta por la Corte Constitucional:

Cuarto. Exhortar al Congreso de la República para que antes del 20 de junio de 2013 legisle, de manera sistemática y organizada, sobre los derechos de las parejas del mismo sexo con la finalidad de eliminar el déficit de protección que, según los términos de esta sentencia, afecta a las mencionadas parejas(577/2011).

Cabe evaluar entonces el por qué a pesar de los pronunciamientos positivos en la materia, que denotan un respeto y garantía a sus derechos, continúan desconociéndose los derechos fundamentales de la comunidad LGBTI, siendo este el marco conceptual que permitirá demostrar puntualmente que, mientras no se promueva ni se cristalice la reforma constitucional del con- cepto de familia que se consigna en el artículo 42 de la Carta Política, cualquier normativa que pretenda otorgar derechos a las parejas del mismo sexo, será inaplicada por las autoridades administrativas y judiciales en atención a que se considerará inconstitucional, generando este trabajo la realización de un acto legislativo que modifique el concepto de familia haciéndolo incluyente, acorde con los cambios connaturales a la sociedad en que vivimos en el presente.

En tal sentido, este documento tiene tres secciones: primera, se efectúa una breve descripción de la situación actual que a diario enfrentan las parejas homosexuales; segunda, se analiza el significado de los derechos a la familia y a la igualdad para quienes forman parte de la comunidad LGBTI. Tercera, se revisan los instrumentos normativos y jurisprudenciales que sobre el tema se han expedido en los ámbitos nacional e internacional; recorrido que además de permitir la evaluación teórica dela problemática planteada, clarificará los fundamentos de la apremiante reforma constitucional del concepto de familia en Colombia.

\section{B. El concepto de familia en el derecho comparado}

Según la Declaración Universal de Derechos Humanos, la familia es el elemento natural y fundamental de la sociedad y tiene derecho a la protección de la sociedad y del Estado (art. 16-3), concepto tradicional que ha venido transformándose en los últimos años a raíz de los avances en materia de protección de los derechos humanos respecto de la población LGBTI.

A pesar de dicho concepto "universal", la sociedad en general aún no ofrece una respuesta absoluta a la pregunta ¿qué es la familia?, ya que dados los cambios sociales y culturales, no existe un consenso sobre su significado, pues con ocasión de las grandes transformaciones sociales que han ocurrido en el mundo, han tenido un impacto significativo en la familia como grupo humano. Tales transformaciones hacen referencia a procesos como la industrialización, 
la urbanización y la incursión de la mujer en las esferas sociales, políticas y educativas (Walters, Cintrón y Serrano, 2006).

Estos factores sociales alteraron la configuración de la familia tradicional en lo atinente a la reducción de su tamaño, el incremento de divorcios, la maternidad precoz y, por supuesto, el surgimiento de nuevas tipologías de familia que no han podido abandonar la concepción de hábitat natural del ser humano (Arés, 2000).

Choque entre tradición y sociedad contemporánea que en ocasiones provoca el estancamiento en el reconocimiento de ciertos derechos a esas nuevas tipologías de familia, pues en países como Puerto Rico, se ha arraigado la idea que reza así: "el modelo de familia nuclear es la estructura familiar ideal y única capaz de proveer balance emocional y seguridad a sus miembros" (Quiles, 1992,pp. 63), siendo de importante connotación jurídica anotar que, dichas necesidades pueden ser provistas por cualquier tipo de familia y no en exclusiva por la familia nuclear, argumentado ello en la definición de familia que a continuación aparece: "grupo de personas que comparten un proyecto de vida en el que se generan sentimientos de dependencia, compromiso entre sus miembros y se establecen relaciones de intimidad y reciprocidad(Palacios y Rodrigo, 2001, p. 33).

Así también, la familia como institución dinámica a través del tiempo se transforma continuamente, tal y como lo plantea Minuchin (1986, p. 93), quien afirma que esa dinámica comprende:

[...] los aspectos suscitados en el interior de la familia, en donde todos y cada uno de los miembros está ligado a los demás por lazos de parentesco, relaciones de afecto, comunicación, límites, jerarquías o roles, toma de decisiones, resolución de conflictos $y$ las funciones asignadas a sus miembros.

Resultando entonces más precisa la aseveración que hacen Estrella y Suárez al respecto:
El estudio de la dinámica familiar describe y analiza un conjunto amplio de características tales como: la propia definición de familia; los aspectos relacionados [con] la composición y grado de parentesco de los miembros del grupo familiar; las relaciones entre ellos, incluidos su nivel de integración o disociación, proximidad o rechazo; sus roles, límites e interacciones; los subgrupos constituidos al interior del grupo familiar, así como las funciones intrínsecas a la familia (2006, p. 39).

Dinámica que se liga al ciclo familiar que describe las siguientes etapas: el matrimonio, el nacimiento del primer hijo, las distintas edades de sus hijos y su posterior independencia, el retiro de la fuerza de trabajo y la muerte de los/as cónyuges; ciclo que por supuesto ha sido objeto de variaciones:

Etapa inicial: pareja joven sin hijos donde la jefa de hogar o cónyuge es menor de 36 años; Etapa I de constitución de familia: hogares donde el hijo mayor del jefe, tiene menos de 13 años; Etapa II de familia: hogares donde el hijo mayor del jefe tiene entre 13 y 18 años. Etapa III de familia: hogares donde el hijo mayor del jefe, tiene 19 años y más; $y$, Etapa del nido vacío: pareja adulta sin hijos, donde la cónyuge es mayor de 35 años y no tienen hijos que vivan con ellos (Arriagada, 1997, p. 14).

Etapas que pueden funcionar de forma análoga en las nuevas clases de familia sin impedimento alguno. No obstante, hay quienes consideran que este ciclo tiende a funcionar solo en familias de tipo nuclear, lo que conlleva cuestionarnos respecto a una posible crisis del concepto de familia, con fundamento en el cambio de valores de la familia tradicional, ya que este modelo se ha sustituido por: familias con madres que trabajan fuera del hogar, familias con padres divorciados, familias formadas por parejas que se casan por segunda vez con o sin hijos, padres solteros, parejas del mismo sexo con o sin hijos, familias extendidas, abuelos con nietos y tutores de menores (Arriagada, 2002). 
Siendo el sentido de esta investigación, determinar las transformaciones de la familia en aras de poder contribuir a la modificación de la realidad familiar en Colombia, vislumbrando en tal sentido que, dados los ciclos disímiles de la familia, se hace necesario reconocer que en la sociedad contemporánea deben aceptarse todas las formas de familia anunciadas, pues tienen un soporte y fundamento social, cultural e histórico que las hace merecedoras de todo el respeto y protección por parte del aparato estatal.

Cabe anotar que se coincide con Dávila (1992) en lo que respecta al progreso y consiguiente modificación que de forma constante vive la sociedad, haciendo hincapié en que dicho proceso se ve influenciado por toda clase de valores que no implican cambio en la concepción de la familia como institución base (p. 1-16). Esta idea, lleva inmersa la vocación de permanencia a través del tiempo que surge como condición necesaria de presencia dentro de la sociedad y que su universalidad histórica y culturalmente diferenciada, la convierte en una institución cambiante que se reconstruye a través del tiempo a tono con su contexto histórico, político y social, lo cual la hace fundamental para el desarrollo individual de cada miembro así como también para la organización social (Walters et al., 2006).

Analizamos ahora lo ocurrido con el tema en el mundo, ejercicio que ayudará a dilucidar la velocidad de algunas culturas y sociedades en aceptar las variaciones y evolución de esta institución social mediante la aceptación normativa del matrimonio entre personas del mismo sexo: Países Bajos (desde 2001), Bélgica (desde 2003),Estados Unidos (desde 2004 en 13 estados), España (desde 2005), Canadá (desde 2005), Sudáfrica (desde 2006), Noruega (desde 2009), Suecia (desde 2009), Portugal (desde 2010), Islandia (desde 2010), Argentina (desde 2010), México (desde 2010), Dinamarca (desde 2012), Uruguay (desde 2013), Nueva Zelanda (desde 2013), Francia (desde 2013) y Brasil (desde 2013)(El Comercio, 17 de julio de 2013).Es decir, desde el año 2001, la sociedad empezó a notar la necesidad de cambio que desde hacía tiempo la población LGBTI exigía. A continuación se esbozará lo concerniente a la materia en algunos de los Estados en mención:

\section{Argentina}

Con la ley 26.618 promulgada el día 21 de julio de 2010, se modificó el Código Civil argentino en lo que respecta al matrimonio civil entre personas del mismo sexo, luego de un fuerte debate parlamentario donde los argumentos centrales fueron de orden moral, religioso, cultural y social.

La modificación se centró básicamente en abolir de todos los artículos del Código Civil, la expresión "marido y mujer", reemplazándola por "contrayentes" o "cónyuges", sin especificar el sexo de los mismos, quedando de esta forma plasmada normativamente la posibilidad para las parejas del mismo sexo de contraer matrimonio, prescribiendo así el Código Civil argentino lo siguiente:

Es indispensable para la existencia del matrimonio el pleno y libre consentimiento expresado personalmente por ambos contrayentes ante la autoridad competente para celebrarlo.

El matrimonio tendrá los mismos requisitos y efectos, con independencia de que los contrayentes sean del mismo o de diferente sexo (Código Civil de Argentina, art. 172).

Acto revestido de toda validez siempre y cuando no falte alguno de los requisitos en mención, pues si esto ocurre, no se producirán efectos civiles aunque las partes hubiesen obrado de buena fe, siendo este precepto el objetivo central de la reforma: establecer la igualdad de derechos para todos los asociados, pregonada desde los principios y valores constitucionales más allá de las deliberaciones que dentro del ámbito privado tomen los individuos.

Entretanto, es de resaltar que el artículo 206 tiene en cuenta las nuevas posibilidades que pueden presentarse cuando los matrimonios constituidos por personas del mismo sexo deciden separarse o divorciarse: 
Separados por sentencia firme, cada uno de los cónyuges podrá fijar libremente su domicilio o residencia. Si tuviese hijos de ambos a su cargo, se aplicarán las disposiciones relativas al régimen de patria potestad.

Los hijos menores de cinco (5) años quedarán a cargo de la madre, salvo causas graves que afecten el interés del menor. En casos de matrimonios constituidos por ambos cónyuges del mismo sexo, a falta de acuerdo, el juez resolverá teniendo en cuenta el interés del menor. Los mayores de esa edad, a falta de acuerdo de los cónyuges, quedarán a cargo de aquel a quien el juez considere más idóneo. Los progenitores continuarán sujetos a todas las cargas y obligaciones respecto de sus hijos (Código Civil de Argentina, art. 206).

A propósito de lo estipulado de forma precedente, es de resaltar que el nuevo inciso $\mathrm{C}$ del artículo 36 de la ley $26.618^{3}$, se preocupa además por concertar de manera garantista los aspectos referentes a la inscripción de los niños recién nacidos en el registro civil, anunciando que:

El nombre y apellido del padre y de la madre o, en el caso de hijos de matrimonios entre personas del mismo sexo, el nombre y apellido de la madre y su cónyuge, y tipo y número de los respectivos documentos de identidad. En caso de que carecieren de estos últimos, se dejará constancia de edad y nacionalidad, circunstancia que deberá acreditarse con la declaración dedos (2) testigos de conocimiento, debidamente identificados quienes suscribirán el acta (Ley 26.618/2010,art. 36, cláusula C).

Ello denota la preocupación de las autoridades argentinas por tutelar de modo absoluto e integral los derechos que devienen de la construcción de esta nueva clase de familia; esto es, Argentina reconoce que las sociedades tienen necesidades que no se acomodan a las leyes existentes, siendo indispensable la modificación de las mismas, partiendo en este punto del hecho de que aun

3 Regula el registro civil y de capacidad de las personas. cuando no exista norma que regule el tema y haya un marcado atraso legislativo, la sociedad no se detendrá en este sentido, es decir, la inexistencia normativa, no impedirá o disminuirá la voluntad de las parejas del mismo sexo de conformar una familia en circunstancias de igualdad con las familias tradicionales.

La anterior descripción demuestra el gran avance legislativo ocurrido en el Estado argentino, pues resulta ser garantista de los derechos a la familia, no solo de quienes contraen matrimonio sino de los hijos que puedan llegar a ser parte de la familia; señalando la cláusula que trae el artículo 42 de esta ley 26.618, ya que además de complementaria es incluyente, debido a que manifiesta que todas la referencias en el ordenamiento jurídico con respecto al matrimonio, serán aplicables al constituido por personas del mismo sexo o distinto sexo:

Todas las referencias a la institución del matrimonio que contiene nuestro ordenamiento jurídico se entenderán aplicables tanto al matrimonio constituido por dos (2) personas del mismo sexo como al constituido por dos (2) personas de distinto sexo.

Los integrantes de las familias cuyo origen sea un matrimonio constituido por dos (2) personas del mismo sexo, así como un matrimonio constituido por personas de distinto sexo, tendrán los mismos derechos y obligaciones.

Ninguna norma del ordenamiento jurídico argentino podrá ser interpretada ni aplicada en el sentido de limitar, restringir, excluir o suprimir el ejercicio o goce de los mismos derechos y obligaciones, tanto al matrimonio constituido por personas del mismo sexo como al formado por dos (2) personas de distinto sexo (Ley 26.618/2010, art. 42).

Este ejercicio normativo evidencia además de lo descrito, el arraigo de una conciencia liberal sin connotaciones políticas o religiosas, quedando claro que la sexualidad debe quedar desprovista 
de todas aquellas superposiciones referentes a la raza, la clase o el género, criterios que terminan por complejizar los asuntos: cuanto menos sexual se vuelva una cuestión, más factible es que se la considere como universal y libre de intereses (Pecheny, 2009).

Se han reconocido así por parte de las autoridades parlamentarias argentinas las nuevas realidades sociales mediante la modificación del ordenamiento jurídico, con el fin de incluir y regular situaciones de hecho, surgiendo la imperiosa necesidad de garantizar derechos $y$ obligaciones que a través del tiempo se han garantizado a las familias tradicionales, generándose tal circunstancia en los componentes del derecho a la igualdad y no discriminación: tratamiento igualitario ante situaciones iguales.

\section{Uruguay}

El día 3 de mayo de 2013 Uruguay aprobó la ley 19.075 denominada "De matrimonio igualitario", la cual modifica algunos de los artículos del Código Civil uruguayo en lo atinente a la institución del matrimonio entre personas del mismo sexo.

Para empezar, el artículo 1 de la nueva ley, modifica el artículo 83 del Código Civil, introduciendo un inciso que establece: "El matrimonio civil es la unión permanente, con arreglo a la ley, de dos personas de distinto o igual sexo"; cambio que elimina las dudas originadas luego de la aprobación de lasleyes $18.246^{4}$ y $18.620^{5}$, acerca de si la heterosexualidad en el matrimonio seguía constituyendo un principio fundamental en el ordenamiento público internacional, pues dada la entrada en vigor de la ley 19.075, resulta inadmisible sostener que el reconocimiento en Uruguay de un matrimonio homosexual celebrado en el extranjero, pudiera contravenir un principio fundamental en el que el Estado ratifica su individualidad jurídica, como lo era el de la heterosexualidad en el matrimonio.

\footnotetext{
Ley sobre Unión Concubinaria.

5 Ley sobre derecho a la identidad de género y al cambio de nombre y sexo en documentos identificatorios.
}

Esta ley, que también logra disipar cualquier duda sobre la calificación de los matrimonios homosexuales oficiados en el extranjero en la categoría matrimonio previsto en el artículo 2.395 del Código Civil uruguayo, en razón a que claramente consagra que: "la ley del lugar de la celebración del matrimonio rige la capacidad de las personas para contraerlo y la forma, existencia y validez del acto matrimonial", es decir, los matrimonios entre parejas del mismo sexo suscitados en otros Estados, es válida en Uruguay. Sin embargo, antes de aprobada la ley 19.075, en la sentencia 1940 de cinco de junio de2012 (Juzgado Letrado de Familia de $28^{\circ}$ Turno, magistrada Dra. María Cristina Crespo),califica la relación jurídica extranjera que alude al matrimonio válidamente celebrado en España entre dos personas del mismo sexo en la categoría matrimonio, regulada por el artículo 2.395 que ya se citó aquí, aclarando que si la calificación dada era posible y apropiada antes de la modificación realizada en el derecho civil interno, luego de ella la misma es obligatoria, lo cual evidencia la preocupación de la autoridad judicial por brindarle protección efectiva a la nueva familia recién constituida.

Resulta entonces lógico afirmar que el artículo 10 de la ley 19.075 en cuanto modifica el numeral $3^{\circ}$ del artículo 187 del Código Civil, que establecía el divorcio "por la sola voluntad de la mujer", ahora fija una posibilidad incluyente: "cualquiera de los cónyuges".

Este cambio de normatividad que se ha referido, da cuenta de lo dicho a lo largo del texto en lo que atañe a las dinámicas sociales y culturales que provocan la alteración de las realidades. El precepto anterior daba cuenta de la situación de inferioridad en que se encontraba la mujer con respecto al hombre, pero en la actualidad, dicha condición ya no se presenta, lo que amerita la inmediata equiparación de ambos cónyuges, sin discriminar por razones de género; debiendo interpretar la norma en relación con el divorcio de todos los matrimonios, ya sean heterosexuales $\mathrm{u}$ homosexuales, siendo el artículo 187.3 incluyente de todas las posibilidades y variantes en cuanto a la composición del matrimonio. 
Es así como en el nuevo ordenamiento civil interno uruguayo que fue modificado por la ley 19.075 , se elimina toda posibilidad de no reconocimiento en el extranjero de una sentencia de divorcio recaída en Uruguay en un proceso voluntario iniciado por uno de los cónyuges, a contrario sensu a lo ocurrido en el pasado, en donde a través de la vulneración del principio de no discriminación por razón de género, la posibilidad de solicitar el divorcio solo estaba en cabeza de la mujer.

Apareciendo sobre el escenario que, la reforma instaurada en el ordenamiento civil uruguayo tiene un sentido normativo inclinado al orden público internacional en lo que respecta a la territorialidad y temporalidad, cuyos valores y principios cambian de un Estado a otro, así como también al interior del territorio nacional conforme el pasar del tiempo.

\section{La discusión jurisprudencial constitu- cional en Colombia sobre los derechos humanos de la comunidad LGBTI}

A pesar de los esfuerzos de organizaciones como Colombia Diversa y de los avances jurisprudenciales que tutelan los derechos fundamentales de la comunidad LGBTI, hoy en día las personas homosexuales siguen siendo víctimas de discriminación. Durante el mes de noviembre de 2013, la iglesia católica colombiana le pidió a la Corte Constitucional abstenerse de fallar a favor de una pareja de lesbianas del departamento de Antioquia que desde el 2009, exige que se le autorice la adopción de la hija biológica de una de ellas.

Los argumentos expuestos por la iglesia católica se circunscriben a afirmar que de ser entregados los menores a parejas homosexuales, se estarían vulnerando sus derechos a la integridad física, psicológica y moral (El Tiempo,18 de noviembre de 2013), exhortando en virtud de ello a las autoridades nacionales a asumir con responsabilidad e independencia sus decisiones sobre la materia frente a la creciente influencia de la ideología de género y las presiones de algunos medios de comunicación y grupos de interés, fundamentadas dichas aserciones en lo consagrado en el artículo 42 de la Constitución Nacional que impregna todo el ordenamiento jurídico nacional.

Declaraciones eclesiásticas que surgen a partir de la solicitud de adopción que hace la pareja de mujeres antioqueñas ante las autoridades nacionales, en razón a que en el año 2005 se casaron en Alemania con las leyes germanas y como cualquier matrimonio, cada una tiene iguales derechos y deberes sobre los hijos que hagan parte de esta unión. Sin embargo, al radicarse en Colombia, las condiciones cambiaron, pues la madre biológica de la menor que pretende adoptar su compañera, es madre soltera y ante las leyes nacionales es la única que tiene responsabilidades sobre su hija, aun cuando en 2008 se formalizó la unión marital (Semana,23 de febrero de 2011).

La preocupación de la comunidad religiosa radica en la posibilidad de que se establezca la adopción de forma general para parejas conformadas por personas del mismo sexo una vez se decida el primer caso positivamente, ello por cuanto los fallos pueden crear jurisprudencia y esta a su vez termina generando normas erga omnes, haciendo énfasis en que en el debate no se exponen argumentos religiosos sino constitucionales ( $E l$ Tiempo, 18 de noviembre de 2013).

Esta tesis que se encuentra revestida de veracidad en lo que respecta a la necesidad de adaptar la Constitución a los requerimientos de una sociedad dinámica, para que la normatividad que hasta la actualidad se ha expedido en procura del bienestar de la comunidad LGBTI, pueda ser aplicada de forma efectiva por parte de todos los operadores jurídicos sin temor a vulnerar la Carta Magna; ha sido un aspecto asentado en la jurisprudencia del sistema interamericano de protección de los derechos humanos así:

La Corte ha establecido, al igual que el Tribunal Europeo de Derechos Humanos, que los tratados de derechos humanos son 
instrumentos vivos, cuya interpretación tiene que acompañar la evolución de los tiempos y las condiciones de vida actuales. Tal interpretación evolutiva es consecuente con las reglas generales de interpretación consagradas en el artículo 29 de la Convención Americana, así como las establecidas por la Convención de Viena sobre el Derecho de los Tratados (Corte Interamericana de Derechos Humanos, 2012, párr. 83).

Es decir, en el marco de las sociedades contemporáneas es lógico que se produzcan cambios sociales, culturales e institucionales encaminados a expedir normatividad y políticas públicas más incluyentes de todas las opciones de vida de sus ciudadanos, lo cual se observa en la aceptación social de parejas interraciales ${ }^{6}$, las madres o padres solteros o las parejas divorciadas, resultando más que apropiado que el derecho y los Estados tengan como deber ayudar al avance social, pues de lo contrario se corre el grave riesgo de legitimar diferentes formas de discriminación violatorias de los derechos humanos.

\section{Los derechos a la familia e igualdad de la población LGBTI}

La protección de los derechos humanos del conglomerado social se encuentra en cabeza de los Estados, lo cual implica que sus esfuerzos deben encaminarse a la creación de políticas públicas orientadas a garantizar a través de medios idóneos los derechos de grupos discriminados y margi-

6 Corte Suprema de Justicia de Estados Unidos de América, Palmore vs. Sidoti, 466 US 429, 433 (25 de abril de 1984), anulando la decisión de un tribunal de otorgarle la custodia de un menor de edad al padre por considerar que la nueva relación de la madre con su nueva pareja de otra raza implicaría un sufrimiento para el niño por la estigmatización social de la relación de la madre. ("La cuestión, sin embargo, es si la existencia de prejuicios privados y la posible vulneración que pueden causar, son consideraciones admisibles para el retiro de un niño de la custodia de la madre natural. Tenemos pocas dificultades para concluir que no los son. La Constitución no puede controlar esos prejuicios, pero tampoco los puede tolerar. Las parcialidades particulares pueden estar fuera del alcance de la ley, pero la ley no puede, directa o indirectamente, permitir su aplicación"). nados de la sociedad, obligación sustentada en los principios y en los derechos constitucionales a la dignidad humana (Constitución Nacional, art. 1), deber de protección de los derechos humanos y libertades (Constitución Nacional, art. 2), derecho a la igualdad y no discriminación (Constitución Nacional, art. 13) y el derecho al libre desarrollo de la personalidad (Constitución Nacional, art. 16).

Derechos que para ser protegidos de forma integral, deben tutelarse desde la óptica de lo preceptuado en el artículo 13 constitucional frente al deber estatal de promover las condiciones de igualdad real y efectiva, adoptando por supuesto medidas en favor de los grupos poblacionales discriminados, tal y como es debido en un Estado social de derecho, en el que se ha denominado esta obligación por la jurisprudencia constitucional como la "cláusula de eliminación de las injusticias presentes":

[...] las autoridades están obligadas -por los medios que estimen conducentes- a corregir las visibles desigualdades sociales, a facilitar la inclusión y participación de sectores débiles, marginados y vulnerables de la población en la vida económica y social de la nación, y a estimular un mejoramiento progresivo de las condiciones materiales de existencia de los sectores más deprimidos de la sociedad (Corte Constitucional, SU225/1998).

Ahora bien, las obligaciones en mención, están incluidas dentro de nuestro ordenamiento jurídico interno a través del bloque de constitucionalidad (Constitución Nacional, arts. 93 y 94), lo cual hace que el artículo 1.1 de la Convención Americana sobre Derechos Humanos tenga plena vigencia nacional, queriendo significar ello que la obligación de los Estados parte de respetar y garantizar el pleno y libre ejercicio de los derechos y libertades allí reconocidos sin discriminación alguna. Es decir, todo tratamiento que pueda considerarse discriminatorio respecto del ejercicio de cualquiera de los derechos garantizados en la Convención es per se incompatible con 
la misma (Corte Interamericana de Derechos Humanos, 1984).

Así, el principio de igualdad ante la ley y la no discriminación se desprende directamente de la unidad de naturaleza del género humano y es inseparable de la dignidad esencial de la persona, frente a la que es incompatible toda situación que, por estimar como superior a un determinado grupo, conduzca a tratarlo con privilegio; o que, a la inversa, por considerarlo inferior, lo trate con hostilidad o que de cualquier forma lo discrimine del goce de derechos que sí se reconocen a quienes no se consideran incursos en tal situación (Corte Interamericana de Derechos Humanos, 1984).

Derechos que en la actual etapa de la evolución del derecho internacional, han ingresado en el dominio del ius cogens, sobre el cual descansa el andamiaje jurídico del orden público nacional $e$ internacional y permean todo el ordenamiento jurídico, implicando ello que los Estados deben abstenerse de realizar acciones que de cualquier modo creen situaciones de discriminación de jure o de facto (Corte Interamericana de Derechos Humanos, 2003).

Conceptos y criterios que se han desarrollado con base en las definiciones de discriminación establecidas en el artículo 1.1 de la Convención Internacional sobre la Eliminación de todas las Formas de Discriminación Racial ${ }^{7}$ y el artículo 1.1 de la Convención sobre la Eliminación de todas las Formas de Discriminación contra la Mujer $^{8}$, afirman que:

7 "En la presente Convención la expresión 'discriminación racial' denotará toda distinción, exclusión, restricción o preferencia basada en motivos de raza, color, linaje $\mathrm{u}$ origen nacional o étnico que tenga por objeto o por resultado anular o menoscabar el reconocimiento, goce o ejercicio, en condiciones de igualdad, de los derechos humanos y libertades fundamentales en las esferas política, económica, social, cultural o en cualquier otra esfera de la vida pública".

8 "A los efectos de la presente Convención, la expresión 'discriminación contra la mujer' denotará toda distinción, exclusión o restricción basada en el sexo que tenga por objeto o resultado menoscabar o anular el reconocimien-
[...] toda distinción, exclusión, restricción o preferencia que se basen en determinados motivos, como la raza, el color, el sexo, el idioma, la religión, la opinión política o de otra índole, el origen nacional o social, la propiedad, el nacimiento o cualquier otra condición social, y que tengan por objeto o por resultado anular o menoscabar el reconocimiento, goce o ejercicio, en condiciones de igualdad, de los derechos humanos y libertades fundamentales de todas las personas (Asamblea General de las Naciones Unidas, 1989, párr. 6).

Lo anterior contrasta con la premisa entregada por Fassin (2003), quien afirma que la cuestión homosexual implica una serie de asuntos que responde al orden de lo simbólico, históricamente definido y modificado por la sociedad, ya que, al otorgar derechos a parejas pertenecientes a la comunidad LGBTI que deciden conformar familia, se estaría contrariando la voluntad popular de algunos sectores conservadores de nuestro país, que están regidos por una jerarquía de valores que en el caso de las prácticas sexuales van de "lo normal", "lo bueno", "lo convencional" y "natural" a lo desviado, "anormal", "promiscuo" y "no reproductivo"(Rubin, 1992).

Esto es, en ocasiones es necesario abandonar los conceptos éticos y religiosos de que de forma casi ancestral han caracterizado a una sociedad, en procura de la promoción del respeto y garantía de los derechos fundamentales de todos los seres humanos que conforman la nación, legitimándose en este sentido, los lazos afectivos y familiares que por años estaban estigmatizados, teniendo ocurrencia una victoria social e histórica ausente hasta ahora en la normatividad nacional.

\footnotetext{
to, goce o ejercicio por la mujer, independientemente de su estado civil, sobre la base de la igualdad del hombre y la mujer, de los derechos humanos y las libertades fundamentales en las esferas política, económica, social, cultural y civil o en cualquier otra esfera".
} 


\section{La jurisprudencia colombiana sobre la protección de los derechos huma- nos de la población LGBTI}

Los derechos a la igualdad y de protección a la familia, se estipulan en un sinnúmero de instrumentos internacionales que consagran lo siguiente: la familia es el elemento natural y fundamental de la sociedad y debe ser protegida por la sociedad y el Estado; los niños tienen derecho a las medidas de protección que su condición de menores requieren por parte de su familia, de la sociedad y del Estado (Declaración Universal de Derechos Humanos, arts. 16 y 25;Declaración Americana de los Derechos y Deberes del Hombre, arts. VI y VII; Pacto Internacional de Derechos Civiles y Políticos, arts. 17, 19, 23 y 24).

Sin embargo, se debe comprender que la constante evolución de la sociedad ha provocado la consolidación de nuevas formas de familia, razón por la cual las autoridades, las normas y la jurisprudencia deben adaptarse a dicho cambio sin interponer conceptos superfluos y tal vez intolerantes, en aras de abandonar el concepto tradicional de familia que en la actualidad resulta obsoleto dadas sus características excluyentes, ello entonces da cabida a aseverar que:

[...] la existencia de un niño en un hogar generalmente basta para constituir una familia como sujeto del derecho a protección, y el niño invariablemente es sujeto no solo de los derechos como tal sino que es beneficiario de los derechos de la familia(O'Donnell, 2004, p. 794).

En tal sentido, la Corte Constitucional aceptó que la presunción de existencia de familia biológica debe ceder ante la denominada familia de crianza que surge cuando:

[...] un menor ha sido separado de su familia biológica y ha sido cuidado por una familia distinta durante un periodo de tiempo lo suficientemente largo como para que se hayan desarrollado vínculos afectivos entre el menor y los integrantes de dicha familia (Corte Constitucional, C-577/2011).
Así mismo, considera que por razones que se soportan en una evaluación ponderada de derechos, resulta preferente la familia de crianza, en atención sobre todo al bienestar y desarrollo de los menores hijos, prevaleciendo siempre el interés superior del niño, lo cual lleva inmerso el deber tanto de las autoridades como de los miembros de la familia y la sociedad, de evitar cualquier tipo de perturbación de los consistentes y firmes vínculos psicológicos y afectivos que se hayan desarrollado en el seno de una familia de crianza.

Aspectos que también deben considerarse dentro de las familias monoparentales, las cuales se caracterizan por estar conformadas por un solo progenitor y los hijos, siendo importante mencionar que las causas que fomentan esta forma de familia son la violencia imperante en Colombia, y los divorcios o separaciones que dan lugar a hogares liderados por uno solo de los padres; convirtiéndose las madres en estas últimas décadas en aquellas personas que asumen las labores de padre y madre dentro de un hogar, generando ello en el legislador la voluntad de proteger este grupo, produciendo normatividad contentiva de una serie de derechos y los modos de hacerlos efectivos para las madres cabeza de hogar ${ }^{9}$, medidas que la Corte ha extendido al hombre que se encuentre en una situación de hecho igual, en virtud del derecho a la igualdad y no discriminación, y por supuesto del propósito de dar cumplimiento al principio de protección del hijo en aquellos casos en que este se encuentre al cuidado exclusivo de su padre, de manera tal que, de no hacerse extensiva tal protección al progenitor podrían verse afectados en forma cierta los derechos de los hijos (Corte Constitucional, C-577/2011).

A continuación, aparecen las familias ensambladas, las cuales se conforman luego de un divorcio o separación, es decir, es el matrimonio

9 Departamento Administrativo para la Prosperidad Social, resolución 03069 de mayo de 2010, ley 1232/2008, decreto reglamentario 1227/2005, ley 861/2003, ley 790/2002, ley 82/1993, entre otras. 
o unión de hecho de una pareja, en la cual uno o ambos integrantes tiene hijos provenientes de una relación previa.

Figuras que dan cuenta de la afirmación inicial, toda vez que el concepto de familia ya no incluye de modo exclusivo a la comunidad natural compuesta por padres, hermanos y parientes cercanos, sino que se amplía, incorporando a personas no vinculadas por los lazos de la consanguinidad, pues por diferentes razones de índole sentimental o económico, resulta necesario sustituir al grupo familiar de origen por uno que cumpla con eficiencia la obligación no solo legal sino también natural de brindar al niño un ambiente acogedor y comprensivo, dentro del cual pueda desenvolverse en todas las etapas de su desarrollo físico, moral, intelectual y psíquico (Corte Constitucional, T-049/1999).

Así mismo, cabe aclarar que el concepto de familia no puede entenderse de manera aislada, sino en concordancia con el principio de pluralismo, toda vez que "en una sociedad plural, no puede existir un concepto único y excluyente de familia, identificando a esta última únicamente con aquella surgida del vínculo matrimonial" (Corte Constitucional, T-572/2009).Pluralismo que a su vez debe interpretarse junto con el derecho a la igualdad descrito por la Corte Interamericana de Derechos Humanos así:

La noción de igualdad se desprende directamente de la unidad de naturaleza del género humano y es inseparable de la dignidad esencial de la persona, frente a la cual es incompatible toda situación que, por considerar superior a un determinado grupo, conduzca a tratarlo con privilegio; o que, a la inversa, por considerarlo inferior, lo trate con hostilidad o de cualquier forma lo discrimine del goce de derechos que sí se reconocen a quienes no se consideran incursos en tal situación de inferioridad. No es admisible crear diferencias de tratamiento entre seres humanos que no se correspondan con su única e idéntica naturaleza (Corte Interamericana de Derechos Humanos, 1984, párr. 55).
En este orden de ideas, se vislumbra que como componente fundamental de la familia, cualquiera sea la forma de la que se hable, se encuentran los hijos, ya sean matrimoniales, extramatrimoniales o adoptivos, pues todos gozan de los mismos derechos según lo dispuesto en el artículo 42 de la Carta Política de Colombia, sin importar si los demás integrantes del núcleo familiar en su conjunto conforman una familia tradicional o por el contrario, un nuevo tipo de familia que aunque diferente en su composición, se reviste de las calidades humanas y valores propios de una familia, ello con soporte en lo que constitucionalmente se consagra como derecho a la libertad de pensamiento y expresión que se consigna en el artículo 13 de la Constitución Política de Colombia y la Convención Americana sobre Derechos Humanos.

Ahora bien, el Estado de Colombia jurisprudencialmente incluyó de forma expresa la protección a ciertos derechos a personas del mismo sexo que han configurado familia, tales derechos son la vocación hereditaria y lo concerniente al régimen patrimonial entre compañeros permanentes:

En sentencia C-238/2012, la Corte Constitucional se pronunció acerca de la vocación hereditaria respecto a la expresión "cónyuge" que aparece en los artículos 1.040, 1.046 y 1.047 del Código Civil, cuando se trata de un compañero o compañera permanente de las parejas con el mismo sexo, advirtiendo que en su jurisprudencia hay una consideración referente a la persona del homosexual, pero también una aproximación a partir de la perspectiva del grupo situado en condición minoritaria y sometido a prejuicios, así como un acercamiento que tiene en cuenta a la pareja integrada por individuos de igual sexo (Corte Constitucional, C-577/2011), en la medida en que, su unión de hecho corresponde a una opción válida que comporta una relación íntima y particular entre dos personas, fundada en el afecto, de carácter exclusivo y singular y con clara vocación de permanencia (Corte Constitucional, T-911/2009).

Es así como jurisprudencialmente, la corporación constitucional brinda protección a las parejas del 
mismo sexo con base en los derechos, garantías y obligaciones que se reconocen a las parejas de heterosexuales que conviven en unión de hecho, empezando por ejemplo, con la declaración de exequibilidad de la ley 54/1990, que regula las uniones maritales de hecho y el régimen patrimonial de los compañeros permanentes con las modificaciones hechas por la ley 979/2005, ello en el entendido que el régimen de protección de dicha normatividad se aplicará también a las parejas homosexuales (Corte Constitucional, C-075/2007).

En cuanto a la seguridad social, se declaró la exequibilidad del artículo 163 de la ley 100/1993 que trata sobre la vinculación al régimen contributivo en materia de salud, lo cual hace que el régimen de protección allí previsto sea también aplicable a las parejas del mismo sexo (Corte Constitucional, C-811/2007), estimando además que las parejas permanentes conformadas por sujetos del mismo sexo son beneficiarias de la pensión de sobrevivientes (Corte Constitucional, C-336/2008), acreditando su condición en la misma forma en que lo hacen las parejas heterosexuales.

Y así también, en lo que respecta a lo siguiente: derechos patrimoniales a las parejas del mismo sexo (Corte Constitucional, C-075/2007); pensiones para el (la) compañero/a permanente del mismo sexo (Corte Constitucional, C-336/2008); derecho de pensión de sobreviviente, igualando los requisitos a las parejas del mismo sexo y las heterosexuales (Corte Constitucional, T-051/2010); $y$, derecho a la porción conyugal de las uniones maritales de hecho y las parejas del mismo sexo (Corte Constitucional, C-283/2011).

No pueden dejarse de mencionar derechos como: patrimonio de familia inembargable y afectación de bienes inmuebles a vivienda familiar; obligación de prestar alimentos; derechos migratorios para las parejas, residir en el departamento de San Andrés y Providencia; garantía de no incriminación en materia penal; beneficio de prescindir de la sanción penal; circunstancias de agravación punitiva; verdad, justicia y reparación de víctimas de crímenes atroces; protección civil a favor de víctimas de crímenes atroces; prestaciones en el régimen pensional y de salud de la fuerza pública; subsidio familiar en servicios; subsidio familiar para vivienda; acceso a la propiedad de la tierra; indemnizaciones del SOAT por muertes en accidentes de tránsito, deberes relacionados con el acceso y ejercicio de la función pública y celebración de contratos estatales (Corte Constitucional, C-029/2009).

Sin embargo, el derecho a tener hijos no ha sido admitido, a pesar del reconocimiento expreso de la Corte frente a la familia que constituyen los miembros de la pareja homosexual que convive permanentemente, entendiendo que el elemento que confiere identidad a la familia no es la heterosexualidad o la consanguinidad, sino el afecto que da lugar a su existencia, fundada en el amor, el respeto y la solidaridad y en la conformación de una unidad de vida o de destino que liga íntegramente a sus miembros e integrantes más próximos (Corte Constitucional, C-238/2012).

Inexplicable es entonces, que el tránsito a la protección y garantía de todos sus derechos fundamentales aún no se materialice, dado el reconocimiento del alto tribunal constitucional colombiano de que la familia que conforman personas del mismo sexo es como las demás, una institución básica y núcleo fundamental de la sociedad, lo cual es razón suficiente para entender que dicha clase de familia merece la protección estatal y social.

Es más, aun cuando existe la ley 1098/2006 (Ley de Infancia y Adolescencia), que regula la adopción por parte de compañeros permanentes de los hijos biológicos del otro compañero, el trámite ha sido denegado por las autoridades competentes en los siguientes términos:

No cumple los fines establecidos en la ley para la adopción "[...] como hombre y mujer, para dar cabida a predicar que existe una unión marital de hecho, porque en Colombia el matrimonio entre parejas homosexuales no tiene ninguna validez, así estos se hayan 
celebrado en el exterior[...] sostuvo que el reconocimiento de nuestra legislación a las parejas del mismo sexo es patrimonial, de derechos pensionales y alimentarios pero no para conformar una familia como lo ordena el artículo 42 citado, que es la conformada por un hombre y una mujer heterosexual, remitiendo a la sentencia C-814 del 2 de agosto de 2001.

[...] el concepto de adopción no se limita a transferir el apellido y el patrimonio, sino al establecimiento de una verdadera familia. Y que las solicitantes no reúnen el aspecto que en su sentir es sustancial: ser una pareja conformada por un hombre y una mujer a fin de continuar con el trámite administrativo ordenados por el artículo 68 del Código de la Infancia y la Adolescencia que sería el del consentimiento y para ilustrar su tesis, transcribió la norma resaltando el siguiente apartado: Del consentimiento: [...] 1. Que esté exento de error, fuerza y dolor y tenga causa y objeto lícito. [...] Es idóneo constitucionalmente cuando quien da el consentimiento ha sido debida y ampliamente informado, asesorado y tiene aptitud para otorgarlo. Se entenderá tener aptitud para otorgar el consentimiento un mes después del día del parto" (Juzgado Primero Penal del Circuito con Funciones de Conocimiento, 2009, Proceso tutela 2009-00390).

Declaración de la defensora segunda de familia, adscrita al Centro Zonal Oriente en Rionegro, Antioquia, durante el trámite de una acción de tutela que solicitaba la protección de los derechos fundamentales de los niños, a la igualdad, el debido proceso, dignidad humana, libre desarrollo de la personalidad, intimidad, buen nombre y a la honra de una familia conformada por dos mujeres y una menor de edad; situación que describe con claridad la incompatibilidad de la normatividad interna colombiana con el corpus iuris internacional, lo cual vulnera abiertamente el precepto establecido en el artículo 2 de la Con- vención Americana sobre Derechos Humanos ${ }^{10}$, denotándose el deber del Estado colombiano de "suprimir las normas y prácticas de cualquier naturaleza que entrañen violación a las garantías previstas en la Convención, así como la expedición de normas y el desarrollo de prácticas conducentes a la efectiva observancia de dichas garantías" (Corte Interamericana de Derechos Humanos, 2005, párr. 189), en lo que respecta a la normativa civil en materia de matrimonios $y$ uniones materiales de hecho entre personas pertenecientes a la comunidad LGBTI, generando con ello una legitimidad de los derechos que como miembros de una familia tienen en estrictas condiciones de igualdad, asegurándose el Estado colombiano de que todos los procedimientos que puedan tener lugar, garanticen el derecho al debido proceso y demás estándares internacionales, cambio que solo puede tener ocurrencia a través de la reforma al artículo 42 de la Constitución Política de Colombia.

\section{Conclusión}

Colombia no puede detenerse al final del camino construido. Después de que el alto tribunal constitucional expidió una serie de sentencias garantistas que demuestra la voluntad de sus integrantes de velar por el respeto de los derechos humanos de todos los ciudadanos colombianos, en estricto cumplimiento de los principios y valores que nos definen como un Estado social y democrático de derecho en el que prevalecen la pluralidad y participación, no puede permitirse el estancamiento de la consolidación de nuevas formas de vida al interior del ordenamiento jurídico nacional.

Por el contrario, luego de la extensa evaluación jurídica y sociológica desarrollada a lo largo de

\footnotetext{
10 "Deber de Adoptar Disposiciones de Derecho Interno. Si el ejercicio de los derechos y libertades mencionados en el artículo 1 no estuviere ya garantizado por disposiciones legislativas o de otro carácter, los Estados Partes se comprometen a adoptar, con arreglo a sus procedimientos constitucionales y a las disposiciones de esta Convención, las medidas legislativas o de otro carácter que fueren necesarias para hacer efectivos tales derechos y libertades".
} 
la tradición argumentativa de la jurisprudencia constitucional, que ha intentado de manera exitosa dar respuesta a las incesantes $e$ insistentes solicitudes de la comunidad LGBTI, es procedente desde todo punto de vista, ampliar el marco jurídico conceptual actual respecto de nociones como: sexualidad, identidad, familia, matrimonio, parentesco, género, entre otras.

Tal y como se pudo establecer de lo documentado en el presente texto, se tiene que no han sido suficientes las expresiones de la Corte Constitucional para blindar jurídicamente la capacidad de las parejas homosexuales para contraer matrimonio bajo el cumplimiento de los propósitos fijados legalmente: cohabitación, fidelidad, socorro y ayuda mutua, pues se cree que dichas obligaciones no las pueden cumplirlos miembros de parejas homosexuales, obviándose en tal sentido que, la constitución de una pareja, lleva inmerso un componente afectivo que estimula su convivencia y que se traduce en acciones solidarias, lo cual significa que la protección de las parejas homosexuales no puede limitarse a los aspectos patrimoniales de su unión permanente.

Así las cosas, no existe un reconocimiento pleno de los derechos humanos de las parejas homosexuales en su esfera familiar, dibujándose ello en una situación compleja de inseguridad jurídica, pues mientras la jurisprudencia constitucional ha decidido tutelar ciertas esferas familiares, por otro lado, se muestra tímida en su mandato al instar al Congreso de la República a legislar sobre la materia de forma definitiva, con el fin de dar solución al déficit de protección que tienen las mencionadas parejas para constituir una familia mediante un contrato marital, formal y solemne con lo cual puedan realizar su proyecto de vida.

La elección de esta opción, resuelve la tensión que se suscita entre la necesidad de adoptar las órdenes judiciales adecuadas para asegurar el goce efectivo del derecho fundamental a tener una familia de las parejas de personas del mismo sexo, y el respeto a las competencias que la Constitución le confiere al poder legislativo en materia de regulación de la familia, pero no soluciona la cuestión de fondo, abriendo las puertas a jueces y notarios para llenar temporalmente el vacío de protección sin una guía suficiente que al menos proporcionará a los operadores jurídicos, elementos y límites concretos de deliberación tendientes a impedir la vulneración de los derechos por un lado, y a establecer el cambio solicitado por la población LGBTI, por el otro, representando este documento la oportunidad propicia para generar la pieza que hacía falta: acto legislativo que modifica el artículo 42 superior.

\section{Referencias}

American Psychological Association. (2014). Orientación sexual y homosexualidad. Disponible en: http://www.apa.org/centrodeapoyo/ sexual.aspx

Arés, P. (2000). Propuesta de un diseño teóricometodológico para la intervención familiar en salud comunitaria. Revista Interamericana de Psicología, 34(2), pp. 57-69.

Arriagada, I. (1997). Políticas sociales, familia y trabajo en la América Latina de fin de siglo. Serie políticas sociales, 21. Santiago de Chile: Comisión Económica para América Latina y el Caribe.

Arriagada, I. (2002). Cambios y desigualdad en las familias latinoamericanas. Revista de la Cepal, 77, pp. 143-161.

Asamblea General de las Naciones Unidas y Comité de Derechos Humanos del Pacto Internacional de Derechos Civiles y Políticos. (1989). Observación general 18: no discriminación. Disponible en: http://www1.umn.edu/humanrts/ gencomm/epcomm18s.html

Benedetti, A. (2012). Informe de ponencia para primer debate al proyecto de LEY 47 de 2012 Senado. Disponible en: http://www.imprenta. gov.co/gacetap/gaceta.mostrar_documento?p_ tipo $=22 \& p \_$numero $=47 \&$ p_consec $=34470$

Colombia Diversa. (2010). Situación de derechos humanos de la población LGBT. Informe alterno 
presentado al Comité de Derechos Humanos de Naciones Unidas. Disponible en: http://www2. ohchr.org/english/bodies/hrc/docs/ngos/ColombiaDiversa_Colombia.pdf

Comité de Derechos Humanos. (1994). Caso Balaguer vs. España. Dictamen del Comité de Derechos Humanos emitido a tenor del párrafo 4 del artículo 5 del Protocolo Facultativo del Pacto Internacional de Derechos Civiles y Políticos. $51^{\circ}$ periodo de sesiones. 29 de julio. Comunicación 417/1990. Disponible en: http://www1.umn.edu/ humanrts/hrcommittee/spanish/417-1990.html

Congreso de la República de Argentina. (21 de julio de 2010). Ley 26.618. Por la cual se modifica el Código Civil argentino - Ley de Matrimonio Igualitario. Disponible en: http:// soydondenopienso.wordpress.com/2010/07/22/ ley-26-618-y-decreto-105410-ley-de-matrimonioigualitario/

Congreso de la República de Colombia. (8 de noviembre de 2006). Ley 1098. Por la cual se expide el Código de la Infancia y la Adolescencia. Disponible en: http://www.alcaldiabogota.gov.co/ sisjur/normas/Norma1.jsp?i=22106.

Corte Constitucional de Colombia. (20 de mayo de 1998). Sentencia SU-225. M. P.: Eduardo Cifuentes Muñoz. Disponible en: http://www. corteconstitucional.gov.co/relatoria/1998/su22598.htm

Corte Constitucional de Colombia. (7 de febrero de 2007). Sentencia C-075. M. P.: Rodrigo Escobar Gil. Disponible en: http://www.corteconstitucional.gov.co/relatoria/2007/c-075-07.htm

Corte Constitucional de Colombia. (16 de abril de 2008). Sentencia C-336. M. P.: Clara Inés Vargas Hernández. Disponible en: http://www. alcaldiabogota.gov.co/sisjur/normas/Norma1. jsp?i $=30895$

Corte Constitucional de Colombia. (7 de diciembre de 2009). Sentencia T-911. M. P.: Nilson Pinilla Pinilla. Disponible en: http://www.corte- constitucional.gov.co/relatoria/2009/t-911-09.htm Corte Constitucional de Colombia. (26 de julio de 2011). Sentencia C-577. M. P.: Gabriel Eduardo Mendoza Martelo. Disponible en: http://www.corteconstitucional.gov.co/relatoria/2011/c-577-11.htm.

Corte Constitucional de Colombia. (22 de marzo de 2012). Sentencia C-238. M. P.: Gabriel Eduardo Mendoza Martelo. Disponible en: http:/www.corteconstitucional.gov.co/ relatoria/2012/c-238-12.htm.

Corte Interamericana de Derechos Humanos. (1984). Propuesta de modificación a la Constitución Política de Costa Rica relacionada con la naturalización. Opinión consultiva OC-4 del 19 de enero. Serie A-4.

Corte Interamericana de Derechos Humanos. (2002). Condición jurídica y derechos humanos del niño. Opinión consultiva OC-17 del 28 de agosto. Serie A-17.

Corte Interamericana de Derechos Humanos. (2003). Condición jurídica y derechos de los migrantes indocumentados. Opinión consultiva OC-18 del 17 de septiembre. Serie A-18.

Corte Interamericana de Derechos Humanos. (2005). Caso Yatama vs. Nicaragua.Excepciones preliminares, fondo, reparaciones y costas. Sentencia de 23 de junio. Serie C-127.

Corte Interamericana de Derechos Humanos. (2010). Caso Comunidad indígena Xákmok Kásek vs. Paraguay. Fondo, reparaciones y costas. Sentencia de 24 de agosto. Serie C-214.

Corte Interamericana de Derechos Humanos. (2012). Caso Atala Riffo y niñas vs. Chile. Fondo, reparaciones y costas. Sentencia de 24 de febrero. Serie C-239.

Dávila, A. (1992). Algunas consideraciones en torno a la familia y el hogar puertorriqueño en vísperas del siglo XXI. Presentación ante la Asamblea Anual de la Sociedad de Honor de Enfermería, Sigma Theta Tau, Capítulo Epsilon 
Lamda Inc. Mayagüez, Puerto Rico, abril de 1992. Declaración Americana de los Derechos y Deberes del Hombre. (1948). Aprobada en la Novena Conferencia Internacional Americana. Bogotá.

Declaración Universal de Derechos Humanos (1948). Adoptada y proclamada por la Asamblea General en su resolución 217 A (III).

Estrella, E. \& Suárez, M. (2006). Introducción al estudio de la dinámica familiar. Revista de Atención Integral de Salud y Medicina Familiar para la Atención Primaria, 1(1), pp. 38-47. Disponible en: http://www.idefiperu.org/RAMNRO1/ cadec1_5.html

Fassin, É. (2003). L'inversion de la question homosexuelle. Revue Française de Psychanalyse, 67(1), pp. 263-284. Disponible en: http://www. cairn.info/revue-francaise-de-psychanalyse-20031-page-263.htm

Juzgado Letrado de Familia de $28^{\circ}$ Turno de Uruguay. (5 de junio de 2012). Sentencia 1940. Juez letrado de familia: María Cristina Crespo. Disponible en: http://asadip.files.wordpress. com/2012/06/sentencia.pdf

Juzgado Primero Penal del Circuito con Funciones de Conocimiento. (4 de noviembre de 2009). Proceso tutela 2009-00390. Juez: María Eugenia Henao Zea. Disponible en:http:// colombiadiversa.org/colombiadiversa/images/ stories/que/ACCIONES_LEGALES/ADOPCION/ TUTELA_MADRES_LESBIANAS.pdf

Minuchin, S. (1986). Familias y terapia familiar. México D. F.: Gedisa.

O'Donnell, D. (2004). Derecho internacional de los derechos humanos. Normativa, jurisprudencia $y$ doctrina de los sistemas universal e interamericano. Bogotá: Oficina en Colombia del Alto Comisionado de las Naciones Unidas para los Derechos Humanos.

Pacto Internacional de Derechos Civiles y Políticos.(1966). Adoptado y abierto a la firma, ratificación y adhesión por la Asamblea General en su resolución 2200 A (XXI).

Palacios, J. \&Rodrigo, M. (2001). La familia como contexto de desarrollo humano. En: M. Rodrigo \& J. Palacios (Coords.) Familia y desarrollo humano (pp. 25-44). Madrid: Alianza Editorial.

Pecheny, M. (2009). La construcción de cuestiones políticas como cuestiones de salud: la 'des sexualización' como despolitización en los casos del aborto, la anticoncepción de emergencia y el $\mathrm{VIH} /$ sida en la Argentina. Ponencia presentada en elXXVIII Congreso Internacional de Lasa, Río de Janeiro (11-19 de junio de 2009).

Periódico El Comercio. (17 de julio de 2013). En 15 países se pueden casar las parejas homosexuales. Disponible en: http://www.elcomercio.com/ mundo/Inglaterra-paises-mundo-matrimoniogay-adopcion_0_957504400.html

Periódico El Espectador. (18 de octubre de 2013). Anulan segundo matrimonio entre parejas gay en Colombia. Disponible en: http:// www.elespectador.com/noticias/judicial/anulansegundo-matrimonio-entre-parejas-gay-colombiaarticulo-453213

Periódico El Tiempo. (18 de noviembre de 2013). Corte 'no puede' autorizar adopción a parejas gays: iglesia.Disponible en: http://www.eltiempo. com/archivo/documento/CMS-13202538

Quiles, I. (1992). Familia y país en la construcción de identidades juveniles. Revista del Ateneo Puertorriqueño, III (9), pp. 59-72.

Revista Semana. (23 de febrero de 2011). La historia de una pareja gay que quiere adoptar. Disponible en: http://www.semana.com/ nacion/articulo/la-historia-pareja-gay-quiereadoptar/235933-3

Rubin, G. (1992). Thinking sex: notes for a radical theory of the politics of sexuality. The lesbian and gay studies reader. Nueva York: Routledge. 
Senado y Cámara de Representantes de la República Oriental del Uruguay. (25 de octubre de 2009). Ley 18.620. Derecho a la identidad de género y al cambio de nombre y sexo en documentos identificatorios. Disponible en: http://tbinternet.ohchr.org/Treaties/CCPR/Shared\%20Documents/URY/INT_CCPR_ADR_URY_15485_S. pdf
Senado y Cámara de Representantes de la República Oriental del Uruguay. (10 de abril de 2013). Ley 19.075. Matrimonio igualitario. Disponible en: http://archivo.presidencia.gub. uy/sci/leyes/2013/05/mec_913.pdf

Walters, K., Cintrón, F. \& Serrano, I. (2006). Familia reconstituida: el significado de "familia" en la familia reconstituida. Psicología Iberoamericana, 14(2), pp. 16-27. 